\title{
Does weather affect biting fly abundance in avian nests?
}

\author{
Josué Martínez-de la Puente, Santiago Merino, Elisa Lobato, Juan Rivero-de Aguilar, \\ Sara del Cerro, Rafael Ruiz-de-Castañeda and Juan Moreno
}

J. Martínez-de la Puente (correspondence), S. Merino, E. Lobato, J. Rivero-de Aguilar, S. del Cerro, R. Ruiz-de-Castañeda and J. Moreno Depart. de Ecología Evolutiva, Mus. Nacional de Ciencias Naturales (CSIC), J. Gutiérrez Abascal 2, E-28006. Madrid, Spain]. E-mail:jmp@mncn.csic.es

\begin{abstract}
Environmental factors may strongly affect avian-biting fly interactions in different ways because insects are heterothermic organisms that depend greatly on environmental variables to activate their metabolism and behaviour. We studied the effects of weather on both blackfly (Simuliidae) and biting midge Culicoides (Ceratopogonidae) abundance in nests of three passerine species: blue tits Cyanistes caeruleus, great tits Parus major and pied flycatchers Ficedula hypoleuca, breeding in the same area. We controlled for different host-related factors (hatching date, brood size and host species). Blackfly abundance was negatively related to minimum temperature. In addition, blackfly and biting midge abundances were negatively affected by wind speed measured at $07.00 \mathrm{~h}$, but blackfly abundance was positively associated to wind speed at $18.00 \mathrm{~h}$. We found higher blackfly and biting midge abundances in nests with larger broods breeding later in the season, and significantly higher biting midge abundance in pied flycatcher nests as compared to tit nests. These results represent, to our knowledge, the first report of both environmental and host-related effects on haematophagous fly abundance in the nests of wild hole-nesting birds.
\end{abstract}

Haematophagous flies are important organisms potentially affecting different host life history traits (Smith et al. 1998, Tomás et al. 2008b). Several factors affect the interactions between these insects and their hosts. Locating hosts is a complex behavioural activity that enhances the probability of contact of these insects with their blood meal source (Sutcliffe 1986). This behaviour is driven by a diversity of stimuli including visual and olfactory cues (Bradbury and Bennett 1974, Sutcliffe 1986, Bowen 1991). Also, environmental factors may strongly affect animal-haematophagous fly interactions in different ways because insects are heterothermic organisms that depend greatly on environmental variables to activate their metabolism and behaviour. An extensive literature on flying insects has reported the concomitant effects of temperature and many other weather variables such as rainfall or wind speed affecting on breeding, abundance, survival and activity of haematophagous species (Shipp et al. 1988, Martin et al. 1994, Bishop et al. 1996, Kettle et al. 1998, Su and Mulla 2001), as well as on host-ectoparasite interactions (i.e. Merino and Potti 1996, Smith et al. 1998). In addition, the role of nest humidity affecting ectoparasite infracommunity structure has also been reported (Heeb et al. 2000). Nevertheless, there is a scarcity of information about the effects of weather on haematophagous fly abundance in avian nests. Smith et al. (1998) reported a decrease in blackfly abundance in red-tailed hawk nests when ambient temperatures were below 148 C. Variation in weather conditions may also partly explain the haematophagous fly abundance found in blue tit nests in different breeding seasons (Tomás et al. 2008a).

Blackflies (Diptera: Simuliidae) are small, dark, stoutbodied insects with a wide geographic distribution (Kettle 1995, Lehane 2005). Most adult blackflies are essentially diurnal, many showing a bimodal behaviour pattern with maximum activity in the early morning and afternoon (McCreadie et al. 1985, Grillet et al. 2005, Lehane 2005). Although there are some reports of nocturnal blackfly activity, the level of activity is low (McCreadie et al. 1985) and there is no evidence of blackflies attacking birds after dark (Bennett 1960). Biting midges in the genus Culicoides (Diptera: Ceratopogonidae) are distributed worldwide, and include more than 1400 species (Mellor et al. 2000). Most biting midges are crepuscular or nocturnal, with activity peaks during the evening and the first half of the night (Marquardt et al. 2000, Lehane 2005). This is the case especially during spring, summer and autumn when a pronounced burst of activity at sunset is found in different biting midge species (Kettle et al. 1998). Both blackfly and biting midge females feed on many animals, including mammals and birds (Kettle 1995, Marquardt et al. 2000, Malmqvist et al. 2004), and play an important role as vectors of a diversity of pathogens (Fallis and Bennett 1958, Mellor et al. 2000, Mullens et al. 2006).

The aim of this study is to identify the effects of different weather variables on blackfly and biting midge abundance 
in nests of three coexisting wild hole-nesting avian species, the blue tit Cyanistes caeruleus, the pied flycatcher Ficedula hypoleuca and the great tit Parus major. These avian species differ in several aspects of their breeding phenology including laying date, brood size and the duration of the nestling period (see Cramp 1998), and we control for these biotic factors in our analysis.

\section{Methods}

Our study was carried out during the spring of 2007 in coexisting populations of great tits, blue tits and pied flycatchers breeding in nest-boxes in a Pyrenean oak Quercus pyrenaica forest (Valsaín, 408 53?74N, 48 01?W, $1.200 \mathrm{~m}$ a.s.l.). Wooden nest-boxes were hung from branches at about $4 \mathrm{~m}$ above the ground. Periodical visits in the course of the breeding season allowed us to record hatching date and brood size of each nest. To capture flying insects, we placed inside and close to the roof of each nestbox a plastic Petri dish $\left(8.5 \mathrm{~cm}\right.$ diameter; $\left.56.7 \mathrm{~cm}^{2}\right)$ with a thinly spread layer of commercially available body gel-oil following the method described and tested by Tomás et al. (2008a). Petri dishes were placed in nest-boxes when nestlings were $10 \mathrm{~d}$ old for great and blue tits and $9 \mathrm{~d}$ old for pied flycatcher nestlings, and they were maintained during a period of $3 \mathrm{~d}$. Tomás et al. (2008a) previously reported that nest boxes without broods attract almost no biting flies. Although daily changes of Petri dishes could provide data to detect daily variation in biting flies activity, this possibility was discarded to reduce avian disturbance during reproduction that could result in nest desertion. When Petri dishes were removed from the nest-boxes, the number of nestlings in each nest was recorded. In the laboratory, we quantified blackfly and biting midge abundance collected in Petri dishes under a binocular lens (Motic K700; 46.5 xmagnification). The results reported here include only control nests from several experiments carried out in our avian populations. We include in these results the treatment group from an experiment supplying snail shells to great and blue tits. This treatment had no significant effect on insect abundance (all $\mathrm{P}>0.34$ ).

The Spanish National Meteorological Institute provided weather data from the nearest meteorological station at Segovia, approximately $9 \mathrm{~km}$ from the study area. This station was selected for offering the most complete records of weather variables than stations closer to the study area. Data from this meteorological station have been previously used to demonstrate effects of weather on several factors related to avian biology in the same study area (Sanz et al. 2003, Lobato et al. 2006). Daily meteorological data provided included maximum and minimum temperature, rainfall and wind speed. The latter variable was recorded at four different times of the day $(00.00,07.00,13.00$ and 18.00, local time GMT+01.00). To estimate temperature and wind speed during the insect sampling period, we calculated the average of each maximum and minimum temperatures and wind speeds recorded at each recording time during the period of vector capture. Also, to estimate the effect of rainfall on vector abundance, we calculated a presence/absence index of precipitation during the sampling period of biting flies.

Statistical analyses were conducted using general linear models (GLM; Statistica version 6.0, StatSoft, Inc. 2001). To investigate the variables affecting blackfly and biting midge abundance we included in the model the avian host species (3 groups), the presence/absence of rainfall, and their interactions as factors, as well as hatching date (a variable reflecting avian reproductive phenology), brood size, average minimum temperature, average maximum temperature and average wind speed as covariables. In order to simplify and because blackflies are considered diurnal while the majority of biting midges are crepuscular (see introduction for more details and references), we included average wind speed recorded at 7.00, 13.00 and 18.00 in the model explaining blackfly abundance and average wind speed recorded at $00.00,7.00$ and 18.00 in the model explaining biting midge abundance. Blackfly and biting midge abundances were logarithmically, $\log 10(x+1)$, transformed to normalize their distributions. Residuals of each model were tested for normality.

\section{Results}

A total of 86 nests (33 blue tit nests, 36 pied flycatcher nests and 17 great tit nests) were included in this study. Hatching date differed between species $\left(F_{2,83}=66.17\right.$, P B 0.001$)$ with great tits breeding earlier in the season followed by blue tits and pied flycatchers. Also, avian species differed in brood size $\left(\mathrm{F}_{2,83}=71.72\right.$, P B 0.001$)$. As expected from the ornithological literature, post-hoc analyses revealed that brood size was lower in pied flycatcher than in blue tits (LSD test, P B0.001) and great tits (P B0.001) while no significant differences between blue and great tits were found $(\mathrm{P}=0.18)$.

Overall, 556 blackflies were captured in nests (Table 1). Results from the model are shown in Table 2 (model: adjusted $r^{2}=0.52$, P B 0.001). Blackfly abundance in avian nests was significantly and negatively associated with the minimum temperature (Fig. 1) and wind speed at 07.00 (Fig. 2), but positively with wind speed at 18.00 . In addition, we found positive associations between blackfly abundance and brood size and hatching date.

Table 1. Prevalence (\%), mean abundance (9SD) and range of infection intensity of blackflies and biting midges captured in nests of great tits Parus major, blue tits Cyanistes caeruleus and pied flycatchers Ficedula hypoleuca during the breeding season of 2007.

\begin{tabular}{lcccccccc}
\hline & \multicolumn{3}{c}{ Blackflies } & & & \multicolumn{2}{c}{ Biting midges } \\
\cline { 2 - 3 } & Prevalence & Abundance & Range & & Prevalence & & Abundance & Range \\
\hline Great tit & 88 & 10.9910 .7 & $0-38$ & & 100 & & 30.2941 .7 & $1-132$ \\
Blue tit & 88 & 9.0911 .3 & $0-43$ & & 94 & & 48.2961 .2 & $0-266$ \\
Pied flycatcher & 56 & 2.193 .5 & $0-18$ & & 100 & & 173.89274 .1 & $5-1587$ \\
\hline
\end{tabular}


Table 2. Results of a general lineal model (GLM) relating the blackfly abundance in avian nests with variables under study. Significant relationships at PB0.05 are marked in bold.

\begin{tabular}{lrrc}
\hline & d.f. & $\mathrm{F}$ & $\mathrm{P}$ \\
\hline Maximum temperature & 1,73 & 0.003 & 0.96 \\
Minimum temperature & 1,73 & 4.00 & 0.049 \\
Wind speed at 07.00 & 1,73 & 8.35 & $\mathrm{~B} 0.01$ \\
Wind speed at 13.00 & 1,73 & 0.09 & 0.77 \\
Wind speed at 18.00 & 1,73 & 4.80 & 0.03 \\
Hatching date & 1,73 & 9.45 & $\mathrm{~B} 0.01$ \\
Brood size & 1,73 & 21.12 & $\mathrm{~B} 0.001$ \\
Presence of rainfalls & 1,73 & 2.06 & 0.16 \\
Avian species & 2,73 & 0.46 & 0.63 \\
Avian species xrainfall interaction & 2,73 & 1.78 & 0.18 \\
\hline
\end{tabular}

The remaining variables included in the model were not significantly associated with blackfly abundance.

Overall, 8,360 biting midges were captured (Table 1). Results from the model are shown in Table 3 (model: adjusted $r^{2}=0.39$, P B 0.001 ). Biting midge abundance was negatively associated with wind speed at 07.00 but positively associated with hatching date and brood size. Also, biting midge abundance was significantly higher in pied flycatcher nests than in tit nests, while differences between nests of blue and great tits were not significant. Finally, biting midge abundance tended to be greater when rainfall events occurred. The remaining variables included in the model were not significantly associated with biting midge abundance.

\section{Discussion}

Here we present the first evidence of a strong effect of weather measured as minimum temperature and wind speed on biting fly abundance in avian nests. Environmental effects on flying insects may vary between insect species, in relation to their specific biological developmental requirements, breeding habitat preferences or their patterns of activity. The close association between weather variables makes it difficult to disentangle the potential differential

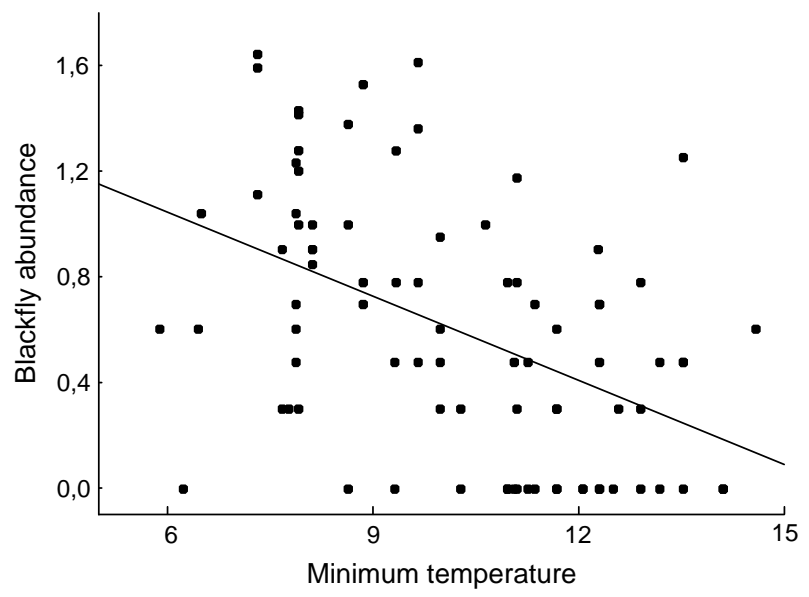

Figure 1. Relationship between average minimum temperature and blackfly abundance (adj. $\mathrm{r}^{2}=0.23$, P B0.001) in avian nests. Blackfly abundance was log10 transformed. Temperature was measured in 8C. Regression line is shown.

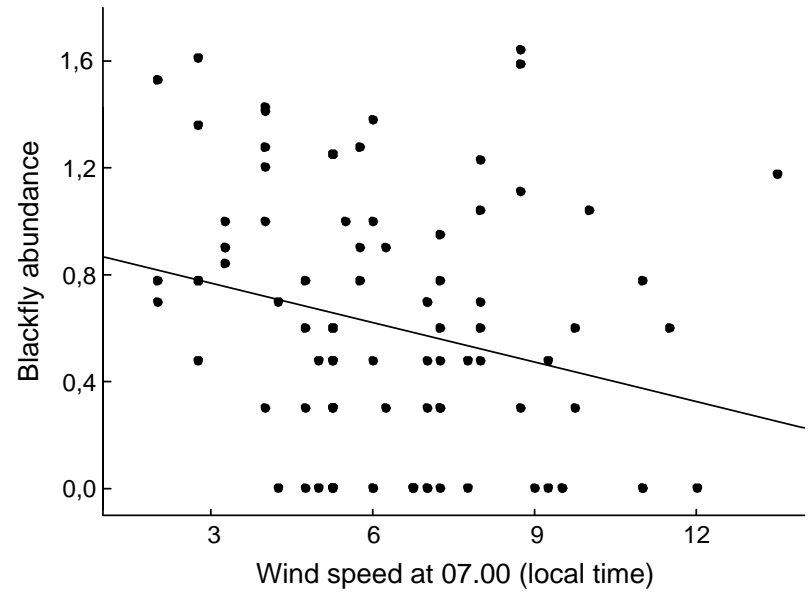

Figure 2. Relationship between average wind speed $(\mathrm{Km} / \mathrm{h})$ measured at 07.00 local time and blackfly abundance (adj. $\mathrm{r}^{2}=0.06, \mathrm{P}=0.02$ ) in avian nests. Blackfly abundance was $\log 10$ transformed. Regression line is shown.

effects of each weather variable on the abundance or activity of biting flies. However, studies in laboratory conditions have found that the flight activity of blackflies varied in response to changes in either temperature or humidity conditions, while the other variable was kept constant (Shipp et al. 1988), suggesting that different combinations of humidity and temperature may affect the activity of these flies. In this respect, according to our results, blackfly abundance decreases with an increase in minimum temperatures suggesting that, in our study area, high minimum temperatures may negatively affect blackfly development or their activity locating hosts. Also, if temperature and rainfall recorded during the capture period were partially related with conditions during previous days, it is possible that an increase in the minimum temperature could directly affect blackfly abundance through its effect on the availability of breeding sites. That is, small streams in our study area usually dry up as temperature increases (authors' pers. obs.) and it is known that blackflies need running water for breeding (Kettle 1995, Lehane 2005). In addition, the positive effect of rainfall events which may directly favour the availability of breeding sites is also partially supported by the marginally positive relationship found between the presence of rainfall and biting midge abundance.

In addition, we also found a clear negative effect of wind speed at 07.00 on both blackfly and biting midge

Table 3. Results of a general lineal model (GLM) relating the biting midge abundance in avian nests with variables under study. Significant relationships at $\mathrm{P}$ B0.05 are marked in bold.

\begin{tabular}{lccc}
\hline & df & $F$ & $P$ \\
\hline Maximum temperature & 1,73 & B0.001 & 0.98 \\
Minimum temperature & 1,73 & 0.05 & 0.82 \\
Wind speed at 00.00 & 1,73 & 0.15 & 0.70 \\
Wind speed at 07.00 & 1,73 & 4.16 & 0.045 \\
Wind speed at 18.00 & 1,73 & 1.96 & 0.17 \\
Hatching date & 1,73 & 7.52 & $\mathrm{~B} 0.01$ \\
Brood size & 1,73 & 8.94 & $\mathrm{~B} 0.01$ \\
Presence of rainfalls & 1,73 & 3.18 & 0.08 \\
Avian species & 2,73 & 5.11 & $\mathrm{~B} 0.01$ \\
Avian species xrainfall interaction & 2,73 & 1.04 & 0.36 \\
\hline
\end{tabular}


abundance in avian nests. It is generally accepted that adult biting midges are nocturnal or crepuscular while the activity of adult blackflies is essentially diurnal, with a peak of activity early in the morning and ceasing with the onset of darkness (Lehane 2005, see more references in introduction). Our results agree with this pattern because higher wind speeds at these times may hinder biting flies from contacting hosts by reducing their flight capacity or affecting their capacity for host-location. Although the degree of the adverse effect of wind speed on insect abundance may vary between insect species (Edwards et al. 1987), it is reported that wind speed is a limiting factor affecting the activity and biting habits of biting flies (Davies 1957, Kettle 1968a,b, Fredeen and Mason 1991, Martin et al. 1994, Marquardt et al. 2000). In addition, Smith et al. (1998) previously suggested that blackfly abundance in avian nests may decrease as wind velocity increases, however in that study authors did not collect systematic data on wind velocity to test this assumption. However, we also found a positive effect of wind speed at 18.00 on the abundance of blackflies in avian nests. The differing effect of wind measured at 07.00 and 18.00 on blackflies could be due to the fact that in the later time temperatures are usually hotter than early in the morning and wind could reduce the ambient temperature, favoring blackflies mobility. In fact, Berzina (1953) (see in Davies 1957) found that wind depressed the blackfly landing activity on man at unfavourable temperatures while stimulated it at optimum temperatures.

Our models explain $52 \%$ of the variance in blackfly abundance and 39\% in biting midge abundance. Models including only the abiotic variables explain $31 \%$ of the variance in blackfly abundance and $20 \%$ in biting midge abundance (see Tables 2 and 3). Previously, it was reported that nest size, nestling condition, female infection status, the abundance of other ectoparasites and parental provisioning rates may also affect the total abundance of haematophagous flies in avian nests (Tomás et al. 2008b). In this sense, our results support the role of biotic factors affecting biting flies? animal-seeking activity, especially those related to phenology, brood size and host species. The association found here between biting fly abundance and hatching date is in accordance with previous studies on biting flies and birds in the same area (Tomás et al. 2008b, Martínez-de la Puente et al. 2009). Another study in Central Spain, also found an increase in blowfly pupae abundance in pied flycatcher nests with the advancing season (Merino and Potti 1995), pointing out to an effect of weather conditions on development and/or activity of flying insects. In addition, if there are differences in quality of early-nesters, relationships among hatching date and biting fly abundances could be partially confounding. We also found a strong positive association between brood size and biting fly abundance. Previously, Anderson and DeFoliart (1961) found that host size, more than other factors, explained Simulium rugglesi abundance being attracted to various bird species, and other studies lend support to the association between brood size of birds and biting fly abundance (Dow et al. 1957, Tomás et al. 2008a, but see Rätti et al. 2006). Moreover, we found a significant difference in biting midge abundance between tit and pied flycatcher nests. This fact also suggests that factors other than brood size, (e.g. chemical cues) or simply the coincidence at the end of the season between the higher biting midge abundance and pied flycatchers breeding period, could affect the differential abundance of these insects in avian nests. This differential preference of biting flies may have implications for disease epidemiology within the different avian species examined in this study.

Finally, our results have implications for the potential impact of climate change on vectors and diseases. For example, during the period 1980-2001 an increase in May daily temperatures has been reported in our study area (Sanz et al. 2003). This implies that if water supply is maintained in the zone an increase in biting flies abundance and diseases transmitted by them could be expected. A better knowledge of determinants of biting fly densities is required given their role in favouring the evolution of high virulence of several important diseases (Ewald 1994).

Acknowledgements - We thank Javier Donés (Director of "Montes de Valsaín") for permission to work in the study area. The Junta de Castilla y León authorized the ringing and handling of birds. This study was funded by project CGL2006-14129-C02-01 from MEC and CGL2007-61251. J. M-P, E. L., S. C. and R. R.-C. were supported by grants from "El Ventorrillo"- CSIC, MEC, CAM and JAE-CSIC respectively. J. R. A. was not supported by any grant. This study is a contribution to the research developed at "El Ventorrillo". The Inst. Nac. de Meteorología provided weather data. This study complies with the current laws of our country. Two anonymous referees considerably improved a previous version of the manuscript with their constructive comments.

\section{References}

Anderson, J. R. and DeFoliart, G. R. 1961. Feeding behaviour and host preferences of some black flies (Diptera: Simuliidae) in Wisconsin. - Ann. Entomol. Soc. Amer. 54: 716-729.

Bennett, G. F. 1960. On some ornithophilic blood-sucking diptera in Algonquin Park, Ontario, Canada. - Can. J. Zool. 38: 377-389.

Berzina, A. N. 1953. Attack of black-files on man in nature. - Zool. Inst. Acad. Sci. USSR, Parasit. Sympos. 15: 353-385.

Bishop, A. L., Mckenzie, H. J., Barchia, I. M. and Harris, A. M. 1996. Effect of temperature regimes on the development, survival and emergence of Culicoides brevitarsis Kieffer (Diptera: Ceratopogonidae) in bovine dung. - Aust. J. Entomol. 35: 361-368.

Bowen, M. F. 1991. The sensory physiology of host-seeking behaviour in mosquitoes. - Ann. Rev. Entomol. 36: 139-158.

Bradbury, W. C. and Bennett, G. F. 1974. Behavior of adult Simuliidae (Diptera). I. Vision and olfaction in near-orientation and landing. - Can. J. Zool. 52: 1355-1364.

Cramp, S. 1998. The complete birds of the western Paleartic on CD-ROM. - Oxford Univ. Press.

Davies, L. 1957. A study of the blackfly, Simulium ornatum Mg. (Diptera), with particular reference to its activity on grazing cattle. - Bull. Ent. Res. 48: 407-424.

Dow, R. P., Reeves, W. C. and Bellamy, R. E. 1957. Field tests of avian host preference of Culex tarsalis Coq. - Am. J. Trop. Med. Hyg. 6: 294-303.

Ewald, P. W. 1994. Evolution of infectious diseases. - Oxford Univ. Press. 
Edwards, P. B., Kettle, D. S. and Barnes, A. 1987. Factors affecting the numbers of Culicoides in traps in coastal southeast Queensland with particular reference to collections of C. subimmaculatus in light traps. - Aust. J. Zool. 35: 469-486.

Fallis, A. M. and Bennett, G. F. 1958. Transmission of Leucocytozoon bonasae Clarke to ruffed grouse (Bonasa umbellus) by the black flies Simulium latipes MG. and Simulium aureum Fries. - Can. J. Zool. 36: 533-539.

Fredeen, F. J. and Mason, P. G. 1991. Meteorological factors influencing host-seeking activity of female Simulium luggeri (Diptera: Simuliidae). - J. Med. Entomol. 28: 831-840.

Grillet, M.-E., Villamizar, N. J., Cortez, J., Frontado, H. L., Escalona, M., Vivas-Martinez, S. and Basanez, M.-G. 2005. Diurnal biting periodicity of parous Simulium (Diptera: Simuliidae) vectors in the onchocerciasis Amazonian focus. - Acta Trop. 94: 139-158.

Heeb, P., Koelliker, M. and Richner, H. 2000. Bird-ectoparasite interactions, nest humidity, and ectoparasite community structure. - Ecology 81: 958-968.

Kettle, D. S. 1968a. The biting habits of Culicoides furens (Poey) and C. barbosai Wirth \& Blanton. I. The 24-h cycle, with a note on differences between collectors. - Bull. Ent. Res. 59: 21-31.

Kettle, D. S. 1968b. The biting habits of Culicoides furens (Poey) and C. barbosai Wirth \& Blanton. II. Effect of meteorological conditions. - Bull. Ent. Res. 59: 241-258.

Kettle, D. S. 1995. Medical and veterinary entomology. 2nd edition. - CAB international.

Kettle, D. S., Edwards, P. B. and Barnes, A. 1998. Factors affecting numbers of Culicoides in truck traps in coastal Queensland. - Med. Vet. Entomol. 12: 367-377.

Lehane, M. 2005. The biology of blood-sucking in insects. Second ed. - Cambridge Univ. Press.

Lobato, E., Moreno, J., Merino, S., Sanz, J. J., Arriero, E., Morales, J., Tomás, G. and Martínez-de la Puente, J. 2006. Maternal clutch reduction in the pied flycatcher: an undescribed clutch size adjustment mechanism. - J. Avian Biol. 37: 637-641.

Malmqvist, B., Strasevicius, D., Hellgren, O., Adler, P. H. and Bensch, S. 2004. Vertebrate host specificity of wild-caught blackflies revealed by mitochondrial DNA in blood. - Biol. Lett. 271: S152-S155.

Marquardt, W. C., Demaree, R. S. and Grieve, R. B. 2000. Parasitology and vector biology. 2nd ed. - Academic Press.

Martin, F. R., McCreadie, J. W. and Colbo, M. H. 1994. Effect of trap site, time of day, and meteorological factors on abundance of host-seeking mammalophilic black flies (Diptera: Simuliidae). - Can. Entomol. 126: 283-289.
Martínez-de la Puente, J., Merino, S., Tomás, G., Moreno, J., Morales, J., Lobato, E., Talavera, S., Sarto, I and Monteys, V. 2009. Factors affecting Culicoides species composition and abundance in avian nests. - Parasitology 136: 1033-1041.

McCreadie, J. W., Colbo, M. H. and Bennett, G. F. 1985. The seasonal activity of hematophagous diptera attacking cattle in insular Newfoundland. - Can. Ent. 117: 995-1006.

Mellor, P. S., Boorman, J. and Baylis, M. 2000. Culicoides biting midges: their role as arbovirus vectors. - Annu. Rev. Entomol. 45: 307-340.

Merino, S. and Potti, J. 1995. Mites and blowflies decrease growth and survival in nestling pied flycatchers. - Oikos 73: 95-103.

Merino, S. and Potti, J. 1996. Weather dependent effects of nest ectoparasites on their bird hosts. - Ecography 19: 107-113.

Mullens, B. A., Cardona, C. J., McClellan, L., Szijj, C. E. and Owen, J. P. 2006. Culicoides bottimeri as a vector of Haemoproteus lophortyx to quail in California, USA. - Vet. Parasitol. 140: 35-43.

Rätti, O., Ojanen, U. and Helle, P. 2006. Increasing group size dilutes black fly attack rate in black grouse. - Ornis Fenn. 83: 86-90.

Sanz, J. J., Potti, J., Moreno, J., Merino, S. and Frías, O. 2003. Climate change and fitness components of a migratory bird breeding in the Mediterranean region. - Global Change Biol. 9: 461-472.

Shipp, J. L., Grace, B. and Janzen, H. H. 1988. Influence of temperature and water vapour pressure on the flight activity of Simulium arcticum Malloch (Diptera: Simuliidae). - Int. J. Biometeorol. 32: 242-246.

Smith, R. N., Cain, S. L., Anderson, S. H., Dunk, J. R. and Williams, E. S. 1998. Blackfly-induced mortality of nestling red-tailed hawks. - Auk 115: 368-375.

Su, T. and Mulla, M. S. 2001. Effects of temperature on development, mortality, mating and blood feeding behavior of Culiseta incidens (Diptera: Culicidae). - J. Vector Ecol. 26: 83-92.

Sutcliffe, J. F. 1986. Black fly host location: a review. - Can. J. Zool. 64: 1041-1053.

Tomás, G., Merino, S., Martínez-de la Puente, J., Moreno, J., Morales, J. and Lobato, E. 2008a. A simple trapping method to estimate abundances of blood-sucking flying insects in avian nests. - Anim. Behav. 75: 723-729.

Tomás, G., Merino, S., Martínez-de la Puente, J., Moreno, J., Morales, J. and Lobato, E. 2008b. Determinants of abundance and effects of blood-sucking flying insects in the nest of a hole-nesting bird. - Oecologia 156: 305-312. 